\title{
Catheter-Associated Urinary Tract Infections: Diagnosis, Treatment, and
} Prevention

\author{
Karen Clarke \\ ${ }^{1}$ Department of ncological Gynecology, Medical University of Lodz,USA.
}

Corresponding Author : Karen Clarke, Department of ncological Gynecology, Medical University of Lodz. USA.

E-mail: karen.clarke@emoryhealthcare.org

Received date: October 29, 2018;Accepted date : December 14, 2018; Published date: February 15, 2019.

Citation : Karen Clarke, Catheter-Associated Urinary Tract Infections: Diagnosis, Treatment, and Prevention, Women Health Care And Issues. Doi: http://dx.doi.org/ 10.31579/ jwhc.2019/006.

Copyright : (c) 2019 Karen Clarke.This is an open-access article distributed under the terms of The Creative Commons Attribution License, whichpermits unrestricted use, distribution, and reproduction in any medium, provided the original author and source are credited.

\begin{abstract}
The most common type of healthcare-associated infection (HAI) is a urinary tract infection (UTI), and 80 percent of these are associated with the use of indwelling urinary catheters (IUCS). These are termed catheter-associated urinary tract infections (CAUTIs). It has been estimated that about 25 percent of all hospitalized patients have an IUC placed during their hospital stay. In addition to the morbidity and mortality that may be associated with a CAUTI, there are also financial consequences. This is particularly true since as of October 1,2008 , the Centers for Medicare and Medicaid Services stopped reimbursing hospitals for several types of infections acquired during a hospital stay, including CAUTIs. In United States (U.S.) the estimated annual cost of treating these CAUTIs is $\$ 350$ million. It has been proposed that a large percentage of CAUTIs should be preventable. This article will discuss the diagnosis, treatment, and prevention of CAUTIs.
\end{abstract}

\section{Introduction}

Based on data submitted to the National Healthcare Safety Network (NHSN) of the Centers for Disease Control and Prevention (CDC) and the Emerging Infections Program Healthcare Associated Infections Community-Interface (EIPHAIC), in 2011 there were 722,000 HAIs in acute care hospitals [1]. On a typical day approximately 4 percent of patients in acute care hospitals have an least one HAI [1,2]. The development of an HAI is associated with increased hospital length of stay (LOS), and also increased morbidity and mortality [2]. HAIs are among the top ten causes of death in the United States [2], and this is reflected by the fact that in 2011, 75,000 patients with HAIs died during their hospital admission. The direct medical cost of treating HAIs is substantial, with estimates as high as between $\$ 28$ billion to $\$ 45$ billion in U.S. hospitals [3]. While other estimated costs of treating HAIs may not be as high as these amounts, they are still high enough to impose a significant financial burden on the health care system [4]. In addition to direct costs to acute care hospitals, HAIs lead to financial losses by affected patients, due to their decreased productivity [3].

The most common type of HAI is the UTI, and 70 to 80 percent of these are due to the use of an IUC [5,6]. This type of infection is termed a CAUTI, and it is responsible for 30 to 40 percent of HAIs [6,7]. In 2011 there were 99,000 CAUTIs in acute care hospitals in the United States [8]. CAUTIs occur more commonly in females compared with males $[10,11]$, and this may be due to some degree, to the shorter urethra that is present in the former. The morbidity and mortality that are associated with CAUTIs are substantially less in comparison with other HAIs that are device-associated, such as ventilator-associated pneumonia (VAP), and central line-associated bloodstream infection (CLABSI) [5].

The extent to which the development of a CAUTI may lengthen a patient's LOS $[5,12]$ or increase mortality $[5,7,9,13,14,15]$ is uncertain. Some authors have concluded that CAUTIs do not contribute to increased mortality in patients who are critically ill [9]. The estimated costs of treating CAUTIs are variable, but symptomatic episodes can cost between $\$ 749$ to $\$ 1007$ for each case [2]. While the cost of treating each CAUTI may not be overwhelming, the high frequency at which this type of HAI occurs magnifies its significance.
During the past few years, many HAIs including CAUTIs, have come to be regarded as preventable complications rather than unavoidable outcomes of medical care $[14,16,17,18,19]$. This change in perspective has created an impetus to substantially reduce the incidence of CAUTIs, and multiple strategies have been explored to achieve this goal $[20,21,22,23,24,25]$. It has been estimated that more than 55 to 70 percent of device-associated infections, including CAUTIs, are preventable through the implementation of uncomplicated procedures $[2,16]$. However, since these procedures are not routinely followed, preventable HAIs continue to develop [2].

\section{Factors That Contribute To Cauti Development}

The risk of developing a CAUTI is directly related to a longer duration of IUC placement $[26,27]$. For catheterized patients, the rate of development of bacteriuria is approximately 3 to $10 \%$ per day $[7,13,28,29]$. There is a $100 \%$ estimated likelihood of developing a CAUTI, for a patient who requires an IUC for greater than or equal to 30 days [28,29]. Bacteremia develops in $4 \%$ of patients who acquire CAUTIs [5]. The two most important factors that lead to the development of CAUTIs are: (1) the inappropriate placement of an IUC, and (2) once an IUC has been placed, leaving it inserted for too long a period of time [27,31].

In order to ensure the timely removal of an IUC, it is important to routinely assess the ongoing need for its continued presence [31]. Unfortunately, $38 \%$ of attending physicians are unaware that their patients have an IUC in place [32], and even when they do know that it is present, the physician may not be fully aware of the infectious and noninfectious consequences that may be associated with its ongoing use. Between 20-50 percent of the time that IUCs are placed, there is no justification for their use [2,7]. Appropriate indications for the placement of an IUC include the following [20]:

- $\quad$ accurate measurement of urinary output in severely ill patients.

- $\quad$ improve comfort for patients receiving end-of-life care.

- acute urinary retention or bladder outlet obstruction.

- $\quad$ the need for a period of prolonged immobilization (e.g. if a patient has a potentially unstable lumbar or thoracic spine, or has multiple traumatic injuries). 
- $\quad$ selected surgical procedures. These include urologic surgeries, as well as those that:

- are expected to have a prolonged duration

- require intraoperative monitoring of urine output

- require the administration of either large volumes of intravenous infusions or diuretics

- $\quad$ To promote healing of open perineal or sacral ulcers.

There are multiple risk factors in a host that can promote the development of a CAUTI [15], but the most important and possibly adjustable one is the length of time that a patient is catheterized. Other risk factors for the development of CAUTI include the following: female gender, urinary tract instrumentation (including the placement of ureteral stents), diabetes mellitus, malnutrition, colonization of the drainage bag, renal disease, pregnancy, azotemia, and catheter insertion outside of the operating room [11,15,33,34].

The formation of bacterial biofilms on the inner and outer surfaces of IUCs is critical for the development of CAUTIs [35,36,37,38,39]. Biofilms are communities of microbes in which the cells are adherent to the IUC surface as well as to each other [35,36]. Almost all bacteria will develop biofilms; however, the organisms that are most commonly develop biofilms on IUCs are Staphylococcus epidermidis, Enterococcus faecalis, Escherichia coli, Proteus mirabilis, Pseudomonas aeruginosa, Klebsiella pneumoniae, as well as other gram negative microbes $[35,38,39]$. Selected organisms, particularly Proteus mirabilis, produce larger amounts of biofilm [40,41].

The bacteria that are present in the biofilm tend to exhibit slow growth, and they grow within a polysaccharide substance. The milieu of the biofilm is such that organisms within it tend to be protected from exposure to antibiotics [35,39]. These characteristics cause the organisms to be less susceptible to antibiotics [36]. The biofilm can serve as an important reservoir of multidrug resistant bacteria [40], and when a mature biofilm has formed, effective treatment necessitates removal of the IUC [42]. The presence of biofilms can contribute to misleading urine culture results [36], in part because the bacteria that comprise it often cannot be cultured [36].

\section{Diagnosis Of CAUTI}

In 2015 the NHSN changed the definition of a CAUTI [8], so that the following criteria be met :

It should also be noted that with this updated definition, Candida species (or yeast not otherwise specified), mold, dimorphic fungi, and parasites cannot be used to meet the CAUTI criteria.

Prior to starting antimicrobial therapy, a urine culture should be collected. This is imperative to allow for identification of the causative organism, especially in view of the possibility that it may be resistant to multiple antibiotics [21]. However, it should be recognized that obtaining urine cultures from patients with long-term IUCs will often yield positive results, but since this often represents colonization, treatment is not warranted in an asymptomatic patient.

It is important to be aware that while pyuria (i.e. $\geq 10$ leukocytes $/ \mu \mathrm{L}$ ) does not confirm the presence of either bacteriuria or a symptomatic UTI, its absence should lead to consideration of alternative diagnoses [43], such as urethritis. Also, it should be recognized that patients with an IUC who develop a CAUTI typically are asymptomatic [44], that is, they do not exhibit the symptoms that are commonly observed with cystitis, such as urgency, dysuria, urinary frequency, or tenderness in the suprapubic area $[21,28]$. However, after removal of the IUC, the symptoms that are commonly associated with cystitis may develop. Many of the signs and symptoms that occur in patients with CAUTIs are imprecise. Autonomic dysreflexia, a feeling of unease, or increased spasticity may be observed in spinal cord injury patients who develop a CAUTI [21].

\section{Treatment}

The optimal duration of antimicrobial therapy for a CAUTI is unclear [21].
If an IUC has been in place for greater than 2 weeks, and is still needed in a patient who requires treatment for a CAUTI, then it should be removed, and replaced with a new one prior to initiating antibiotic therapy $[15,21]$. This strategy accelerates symptom resolution, and also reduces the likelihood of developing another CAUTI [21]. Collection of a urine culture from the newly placed catheter should be completed before administering the first dose of antimicrobial therapy [21].

Antimicrobial therapy should be selected based on the urine culture results $[15,21,45]$. However, it is often necessary to initiate antimicrobial therapy empirically, i.e. before the causative organism that has identified. In such instances, the choice of antibiotic therapy will need to be adjusted when the urine culture results become available. The utilization of either a local or regional antibiogram is a very useful tool to guide appropriate selection of the most effective antibiotic therapy. In order to reduce the likelihood of the development of resistance to antibiotics, when feasible antimicrobials that have a narrow spectrum of coverage are preferred over those with a very broad range of coverage.

For patients who have short-term IUCs (i.e. those placed for less than 30 days), Escherichia coli is the most common cause of CAUTIs [34]. Other organisms that cause CAUTIs less frequently in patients with short-term catheters include Pseudomonas aeruginosa, other Enterobacteriaceae (such as Klebsiella spp. and Enterobacter spp.), Enterococcus spp. , yeast spp., and Staphylococcus aureus [34].

CAUTIs that develop in patients who have long-term IUCs (i.e. those placed for 30 days or longer), tend to be polymicrobial [34]. Additionally, the isolated pathogens often exhibit resistance to multiple antibiotics [21]. In addition to the organisms that commonly cause CAUTIs in patients with short-term catheters, Proteus mirabilis, Morganella morganii, and Providencia spp are frequent causes of CAUTIs in those with long-term IUCs [34].

The Infectious Diseases Society of America (IDSA) recommends that for patients whose symptoms respond promptly to the prescribed antibiotic regimen, a seven day course of treatment is adequate [21]. However, a ten to fourteen day course of treatment is recommended for patients4who have a tardy response to their antibiotic therapy [21]. The length of treatment remains the same whether or not the patient remains catheterized [21]. The strength of the evidence supporting these two recommendations is AIII [21]. The IDSA has suggested that a five day course of Levofloxacin (Levaquin) may be adequate for a patient with a CAUTI who is not severely ill. The strength of the evidence supporting this recommendation is B-III [21]. For a woman who is $\leq 65$ years old and develops a CAUTI which is not associated with symptoms in her upper urinary tract, a three day course of antibiotics may be sufficient, that is, after removal of the IUC. The strength of the evidence that supports this recommendation is B-II [21].

Antifungal therapy is not always necessary for patients who have asymptomatic funguria, since this finding may be due to colonization $[46,47]$. However, for patients who have symptomatic funguria or are hemodynamically unstable, treatment with an antifungal agent is appropriate [46]. Either removal or replacement of the IUC is important for the treatment of patients with funguria, since for between 20-40 percent of patients doing so will promote its clearance, i.e. without the administration of antifungal therapy [46,47]. Treatment options that are available for the treatment of funguria include: fluconazole (which is favored for the treatment of funguria), flucytosine (which must be used with caution, due to its toxicity), amphotericin $\mathrm{B}$, and echinocandins (which have a less clear role than the three aforementioned agents)

\section{STRATEGIES TO HELP PREVENT THE DEVELOPMENT OF CAUTIS}

Guidelines to reduce the CAUTI rate have been published by the U.S. Centers for Disease Control and Prevention (CDC), European Association of Urology (EAU), Healthcare Infection Control Practices Advisory Committee (HICPAC), Infectious Diseases Society of America (IDSA), and Society for Healthcare Epidemiology of America (SHEA) $[20,21,22,23,24,25,26]$ 
Since placement of an IUC is necessary for the development of a CAUTI, if possible, an alternative means to drain the urinary bladder, such as a condom catheter, or intermittent catheterization, should be considered [27,48]. Both of these alternatives are associated with a reduced CAUTI risk, compared with prolonged placement of an IUC [27]. A substantial decrease in UTI (33 versus 12 percent; $\mathrm{P}=0.03$ ) was found when comparing intermittent versus indwelling urinary catheterization [49]. Patients also have expressed a preference for the use of intermittent catheterization compared with indwelling catheterization [50]. Bladder scanning can reduce the CAUTI rate by decreasing the rate of IUC placement [15]

The use of condom catheters rather than IUCs has been associated with favorable outcomes. A randomized trial [51] demonstrated that the likelihood of developing bacteriuria or symptomatic UTI, or experiencing death was five times higher with the use of an IUC, compared with a condom catheter. Patients also found that the condom catheter was less uncomfortable than the IUC [51].

Proper aseptic technique must be followed for IUC insertion, and appropriate catheter care is necessary to reduce the risk of CAUTI development [20]. Catheter care includes maintenance of a closed drainage system, such that replacement of both the catheter and the collection system is necessary, if any defect in the closed drainage system is noted [27].

The use of antibiotic-impregnated catheters does not lead to clinically significant reductions in CAUTI rates [53]. Biofilms, which are the pathogenic basis for the development of CAUTIs [54], colonize all types of catheters, including those that are either silver-coated or antibiotic-impregnated. It has been demonstrated that antibioticimpregnated catheters decrease the risk of developing a CAUTI only during the first week of IUC placement [37]. Similarly, silver alloy catheters show efficacy for reducing the CAUTI rate only during the first two weeks of catheterization [37].

Nurse-driven protocols and checklists provide nurses with a degree of autonomy to remove IUCs that no longer need to remain inserted [55,56]. Utilization of such protocols has been associated with a reduction in the use of unnecessary catheters, as well as lower CAUTI rates $[55,56]$.

Although they are commonly used by only a relatively small percentage of hospitals [57], the use of automatic stop orders and catheter removal reminders are useful to reduce the duration of IUC placement $[27,57,58,59]$. Catheter removal reminders can be physical, e.g. a paper-based reminder [60] or virtual, where an electronic device prompts physicians and nurses to consider removal of the IUC [27].

It has been shown that inadequate nurse staffing is another factor that can contribute to an increased rate of CAUTIs (as well as other HAIs) [61]. A definite association between the occurrence of CAUTIs, and the patient-to-nurse ratio has been demonstrated [61], and it has been suggested that taking steps to reduce "burnout" in nursing staff may be beneficial to reduce infection rates.

Unfortunately, many hospitals still do not accurately document which patients have IUCs in place, or their length of use of IUCs [57]. Also, it has been observed that hospitals tend to be more aggressive about implementing steps to reduce the rates of more costly HAIs, such as VAPs (ventilator-associated pneumonias) and CLABSIs (central lineassociated bloodstream infections), compared with those that would positively impact the CAUTI rate [58]. Since CAUTIs are largely preventable, concerted efforts to follow recommendations to reduce their incidence would be expected to yield significant reductions in the rate of this type of HAI.

\section{Summary}

CAUTIs are the most common type of HAI, and they may be associated with increased morbidity, hospital LOS, and patient costs. In many instances, CAUTIs are preventable. The CDC, EAU, HICPAC, IDSA, and SHEA have formulated extensive guidelines that can be implemented to reduce the CAUTI rate $[20,21,22,23,24,25,26]$.
The two most important actions that can be taken to reduce the incidence of CAUTIs are to limit the placement of IUCs to instances of true necessity, and also to reduce the duration of IUC placement to the short possible length of time. The use of proper techniques for the insertion and maintenance of IUCs is also recommended to help reduce CAUTI rates.

\section{References}

1. Centers for Disease Control and Prevention. Estimates of healthcareassociated infections. http://www.cdc.gov/ncidod/dhqp/hai.html. Accessed September 27, 2018.

2. Calfee D. Crisis in hospital-acquired, healthcare-associated infections. Annu Rev Med 2012;63: 359-371.

3. Scott R. 2009. The direct medical costs of healthcare-associated infections in U.S. hospitals and the benefits of prevention. Centers for Disease Control and Prevention. http://www.cdc.gov/ncidod/dhqp /pdf/Scott_CostPaper.pdf. Accessed September 27, 2018.

4. Zimlachman E, Henderson D, Tamir O, Franz C, et al. Health care associated infections. A meta-analysis of costs and financial impact on the US health care system. JAMA Intern Med 2013; 173(22):2039-2046.

5. Nicolle LE. Catheter-acquired urinary tract infection: the once and future guidelines. Infect Control Hosp Epidemiol 2010;31:327-329.

6. Weber DJ, Sickbert-Bennett EE, Gould CV, Brown VM, et al. Incidence of catheter-associated and noncatheter-associated urinary tract infections in a healthcare system. Infect Control Hosp Epidemiol 2011;32:822-823.

7. Tiwari MM, Charlton ME, Anderson JR, Hermsen ED, et al. Inappropriate use of urinary catheters: a prospective observational study. Am J Infect Control 2012;40:51-54.

8. Urinary tract infection (catheter-associated urinary tract infection [CAUTI] and non-catheter-associated urinary tract infection [UTI]) and other urinary system infection [USI]) events. Centers for Disease Control and Prevention website.http://www.cdc.gov/nhsn/pdfs/pscManual/7pscCauticurrent.p df. Published January 2016. Accessed September 27, 2018.

9. Clec'h C, Schwebel C, Francais A, Toledano D, et al. Does catheterassociated urinary tract infection increase mortality in critically ill patients? Infect Control Hosp Epidemiol 2007;28:1367-1373.

10. Tambyah P, Halvorson K, Maki D. A prospective study of pathogenesis of catheter-associated urinary tract infections. Mayo Clin Proc 1999;74:131-136.

11. Maki DG, Tambyah PA. Engineering out the risk for infection with urinary catheters. Emerg Infect Dis 2001;7(2):342-347.

12. Nelson R, Nelson S, Khader K, Perencevich E, et al. The magnitude of time-dependent bias in the estimation of excess length of stay attributable to healthcare-associated infections. Infect Control Hosp Epidemiol 2015;36(9):1089-1094.

13. Goolsarran VJ, Katz TF. Do not go with the flow, remember indwelling catheters. J Am Geriatrics Soc 2002;50:1739-1740.

14. Chant C, Smith OM, Marshall JC, Friedrich JO. Relationship of catheter-associated urinary tract infection to mortality and length of stay in critically ill patients: a systematic review and meta-analysis of observational studies. Crit Care Med 2011;39(5):1167-1173.

15. Lobdell KW, Stamou S, Sanchez JA. Hospital-acquired infections. Surg Clin N Am 2012;92:65-77.

16. Umscheid CA, Mitchell MD, Doshi JA, Agarwal R, et al. Estimating the proportion of healthcare-associated infections that are reasonably preventable and the related mortality and costs. Infect Control Hosp Epidemiol 2011;32(2):101-114.

17. Bernard MS, Hunter KF, Moore KN. A review of strategies to decrease the duration of indwelling urethral catheters and potentially reduce the incidence of catheter-associated urinary tract infections. Urol Nursing 2012; 32(1): 29-37.

18. Milstein A. Ending extra payment for "Never events" - stronger incentives for patients' safety. New Engl J Med 2009;360:2388-2390.

19. Klompas M, Yokoe DS. Automated surveillance of health careassociated infections. Clin Infect Dis 2009;48:1268-1275. 
20. Gould C, Umscheid C, Agarwal R, Kuntz G, et al. Healthcare Infection Control Practices Advisory Committee (HICPAC): Guideline for the prevention of catheter-associated urinary tract infections, 2009. Available from: http://www.cdc.gov /hicpac/pdf/CAUTI/CAUTIguideline2009final.pdf.

21. Hooton TM, Bradley SF, Cardenas DD, Colgan $\mathrm{R}$, et al. Diagnosis, prevention, and treatment of catheter-associated urinary tract infection in adults: 2009 International Clinical Practice Guidelines from the Infectious Diseases Society of America. Clin Infect Dis 2010;50:625-663.

22. Conway LJ, Larson EL. Guidelines to prevent catheterassociated urinary tract infection: 1980 to 2010. Heart and Lung 2011;41(3):271-283.

23. Greene L, Marx J, Oriola S. APIC elimination guide: guide to the elimination of catheter-associated urinary tract infections (CAUTIs). Available from: http://www.apic.org.

24. Yokoe DS, Mermel LA, Anderson DJ, Arias KM, et al. A compendium of strategies to prevent healthcare-associated infections in acute care hospitals. Infect Control Hosp Epidemiol 2008;29:S12-S21.

25. Smith PW, Bennett G, Bradley S, Drinka P, et al. SHEA/APIC Guideline: Infection prevention and control in the long-term care facility. Am J Infect Control 2008;36:504-535.

26. Lo E, Nicolle L, Coffin S, Gould CV, et al. Strategies to prevent catheter-associated urinary tract infections in acute care hospitals: 2014 update. Infect Control Hosp Epidemiol 2014;35:464-479.

27. Tambyah PA, Oon J. Catheter-associated urinary tract infection. Curr Opin Infect Dis 2012;25: 365-370.

28. Nicolle LE. Urinary catheter-associated infections. Infect Dis Clin N Am 2012;26:13-27.

29. Titsworth WL, Hester J, Correia T, Reed R, et al. Reduction of catheter-associated urinary tract infections among patients in a neurological intensive care unit: a single institution's success. J Neurosurg 2012; 116:911-920.

30. Djeribi R, Bouchloukh W, Jouenne $\mathrm{T}$, Menaa B. Characterization of bacterial biofilms formed on urinary catheters. Am J Infect Control 2012;40:854-859.

31. Fakih MG, Watson SR, Greene T, Kennedy EH, et al. Reducing inappropriate urinary catheter use. Arch Intern Med 2012;172(3):255-260.

32. Saint S, Wiese J, Amory JK, Bernstein ML, et al. Are physicians aware of their patients have an indwelling urinary catheter? Am J Med 2000;104:476-480.

33. Gray M. Reducing catheter-associated urinary tract infection in the critical care unit. AACN Advanced Critical Care 2010;21(3):247-257.

34. Mohajer M, Darouiche R.Prevention and treatment of urinary catheter-associated infections.Curr Infect Dis Rep 2013;15:116123.

35. Donlan R. Biofilms and device-associated infections. Emerg Infect Dis 2001;7(2):277-281.

36. Choe HS, Son SW, Choi HA, Kim HJ, et al. Analysis of the distribution of bacteria within urinary catheter biofilms using four different molecular techniques. Am J Infect Control 2012;40:e249-254.

37. Johnjulio WK, Fuge LH, Srivastava S, Post C. Clinical application of treating biofilms-associated infections in family medicine. Southern Medical Journal 2012;105(1):30-35.

38. Niveditha S, Pramodhini S, Umadevi S, Kumar S, et al. The isolation and the biofilm formation of uropathogens in the patients with catheter associated urinary tract infections. J Clinical and Diagnostic Research 2012; 6(9):1478-1482.

39. Guiton PS, Hung CS, Hancock LE, Caparon MG, et al. Enterococcal biofilm formation and virulence in an optimized murine model of foreign body-associated urinary tract infections. Infect Immun 2010;78(10):4166-4175.

40. Cimiotti JP, Aiken LH, Sloane DM, Wu ES. Nurse staffing, burnout, and healthcare-associated infection. Am J Infect Control. 2012; 40: 486-490.
41. Hola V, Peroutkova T, Ruzika F. Virulence factors in Proteus bacteria from biofilm communities of catheter-associated urinary tract infections. FEMS Immunol Med Microbiol 2012;65:343-349.

42. Jacobsen S, Shirtliff M. Proteus mirabilis biofilms and catheterassociated urinary tract infections. Virulence 2011;2(5):460-465.

43. Dohnt K, Sauer M, Muller M, Atallah K, et al. An in vitro urinary tract catheter system to investigate biofilm development in catheterassociated urinary tract infections. J Microbiol Methods 2011;87:302-308.

44. Wilson ML, Gaido L. Laboratory diagnosis of urinary tract infections in adult patients. Clin Infect Dis 2004;38(8):1150-1158.

45. Tambyah P, Maki D. Catheter-associated urinary tract infection is rarely symptomatic. A prospective study of 1497 catheterized patients. Arch Intern Med 2000;160:678-682.

46. Loeb M, Bentley DW, Bradley S, Crossley K, et al. Development of minimum criteria for the initiation of antibiotics in residents of longterm care facilities: results of a consensus conference. Infect Control Hosp Epidemiol 2001;22:120-124.

47. Wagenlehner FME, Cek $M$, Naber $K G$, Kiyota $H$, et al. Epidemiology, treatment and prevention of healthcare-associated urinary tract infections. World J Urol 2012;30:59-67.

48. Fisher JF, Sobel JD, Kauffman CA, Newman CA. Candida urinary tract infections - treatment. Clin Infect Dis 2011;52(S6):S457-S466.

49. Kauffman C, Vazquez J, Sobel J, Gallis H, et al. Prospective multicenter surveillance of funguria in hospitalized patients. Clin Infect Dis 2000;30(1):14-18.

50. Wyndaele JJ, Brauner Annelie, Geerlings SE, Bela K, et al. Clean intermittent catheterization and urinary tract infection: review and guide for future research. BJU Intern 2012 doi:10.1111/j.1464410X.2012.11549.x

51. Hakwoort RA, Thijs SD, Bouwmeester FW, Broekman AM, et al. Comparing clean intermittent catheterization and transurethral indwelling catheterization for incomplete voiding after vaginal prolapse surgery: a multicenter randomized trial. BJOG 2011; 118: 1055-1060.

52. Hakvoort RA, Nieuwkerk PT, Burger MP, Emanuel MH, et al. Patient preferences for clean intermittent catheterization and transurethral indwelling catheterization for treatment of abnormal post-void residual bladder volume after vaginal prolapsed surgery. BJOG 2011; 2011: 1324-1328.

53. Saint S, Kaufman SR, Roger M, Baker P, et al. Condom versus indwelling urinary catheters: a randomized trial. JAGS 2006;54: 1055-1061.

54. Pickard R, Lam T, MacLennan G, Starr K, et al. Antimicrobial catheters for reduction of symptomatic urinary tract infection in adults requiring short-term catheterization in hospital: a multicenter randomized controlled trial. Lancet 2012;380:1927-1935.

55. Foxman B, Wu J, Farrer E, Goldberg D, et al. Early development of bacterial community diversity in emergently placed urinary catheters. BMC Research Notes 2012;5:332. doi:10.1186/1756-0500-5-332.

56. Parry M, Grant B, Sestovic M. Successful reduction in catheterassociated urinary tract infections: Focus on nurse-directed catheter removal. Am J Infect Control 2013;41:1178-1181.

57. Fuchs MA, Sexton DJ, Thornlow DK, Champagne MT. Evaluation of an evidence-based, nurse-driven checklist to prevent hospitalacquired catheter-associated urinary tract infections in intensive care units. J Nurs Care Qual 2011; 26(2):101-109.

58. Saint S, Kowalski CP, Kaufman SR, Hofer TP, et al. Preventing hospital-acquired urinary tract infection in the United States: a national study. Clin Infect Dis 2008;46:243-250.

59. Krein SL, Kowalski CP, Hofer TP, Saint S. Preventing hospitalacquired infections: a national survey of practices reported by U.S. hospitals in 2005 and 2009. J Gen Intern Med 2011;27(7):773-779.

60. Meddings J, Rogers MA, Macy M, Saint S. Systematic review and meta-analysis: reminder systems to reduce catheter-associated urinary tract infections and urinary catheter use in hospitalized patients. Clin Infect Dis 2010;51(5):550-560. 